\title{
Muliple Sclerosis, Corpus Callosum \& Epilepsy
}

Khin Maung Bo

Rehabilitation Medicine Service, Brigg, Uk

*Corresponding Author: Khin Maung Bo, Rehabilitation Medicine Service, Brigg, North Lincolnshire Uk,

Received date: July 15, 2021; Accepted date: July 28, 2021; Published date: August 06,2021

Citation: Khin Maung Bo. (2021) Muliple Sclerosis, Corpus Callosum \& Epilepsy. J. Neuroscience and Neurological Surgery. 9(3); DOI: $10.31579 / 2578-8868 / 199$

Copyrights: () 2021 Khin Maung Bo, This is an open-access article distributed under the terms of The Creative Commons Attribution License, which permits unrestricted use, distribution, and reproduction in any medium, provided the original author and source are credited
Abstract: general population.
Keywords: multiple sclerosis; epilepsy; corpus callosum; re-entrant circuit

There is a difference in prevalence of Epilepsy in General population \& MS patients. Interical Epileptiform Discharges (IED) positivity in EEG is also different in the above two populations. Demyelination slows down the conduction speed of axons and author is proposing that different speed of conduction in adjacent axons can generate re-entrant circuits. If the reentrant circuits involve Corpus callosum (CC) fibers, seizure activities of MS can be triggered. DBS applied to CC can terminate the seizure attack of MS like Vagal Nerve Simulator (VNS) in terminating seizure in

\section{Abbreviations:}

$\mathbf{A V}=$ Atrioventricular, $\mathbf{C C}=$ Corpus callosum, $\mathbf{D B S}=$ Deep Brain Stimulation, IED= Interictal Epileptiform Discharge, $\mathbf{R E C}=\mathrm{Re}$-entrant circuit, SVT = Supraventricular tachycardia, VNS= Vagal Nerve Stimulator, VICS $=$ Variation in conduction speed

\section{Introduction:}

Epilepsy in general population:
The prevalence of epilepsy in general population is $0.97 \%$ (Joint Epilepsy Council of the UK and Ireland 2011). Standard investigation for Epilepsy is EEG, looking for IEDs but only in about one third of epileptic patients showed IEDs on EEG.

\section{Epilepsy in MS sufferers:}

According to my experience, the prevalence of Epilepsy in Multiple Sclerosis population is around $4 \%$ and EEG in this population does not show IEDs.

The comparison between the two populations is described in Table 1,

\begin{tabular}{|l|c|c|}
\hline & MS patients & General population \\
\hline Prevalence of Epilepsy & $4 \%$ & $0.9 \%$ \\
\hline IED positivity in EEG & $\sim 33 \%$ & $0 \%$ \\
\hline MRI Brain scan & Normal CC thickness & Thinning of CC \\
\hline Treatment & AED, GA & AED, GA, DBS \\
\hline
\end{tabular}

Abbreviations:

$\boldsymbol{A E D}=$ Antiepileptic drug, $\boldsymbol{C C}=$ Corpus Callosum, $\boldsymbol{D B S}=$ Deep Brain Stimulation, $\boldsymbol{E E G}=$ Electroencephalogram, $\boldsymbol{G A}=$ General anesthesia, $\boldsymbol{I E D}=$ Interictal Epileptiform Discharge, $\mathbf{M S}=$. Multiple Sclerosis,

Table 1: Comparison between Epilepsy in General Population \& MS sufferers

\section{Materials and methods:}

To propose a concept that can explain the difference in prevalence between general population and MS patients

\section{Results and Discussion:}

In MS, it is the white matter axons that are affected by demyelination. As we all know, demyelination slows down the conduction speed in the axons. The speed of conduction in axons will vary depending on the extent of demyelination in the axons. This will result in variations in conduction speed (VICS). VICS can create Re-entrant circuits (REC). It is like in Atrio-ventricular re-entrant circuits of AV conduction bundle in the heart. The RECs in AV conduction bundle can trigger Paroxysmal SVTs and can even lead to Cardiac arrest.

In the brain, the $\mathrm{CC}$ (containing millions of axons) connects the two sides of the brain and the conduction is in both directions. It is the most likely 
potential point where re-entrant circuits can occur if there is VICS in the axons (Figure 1).

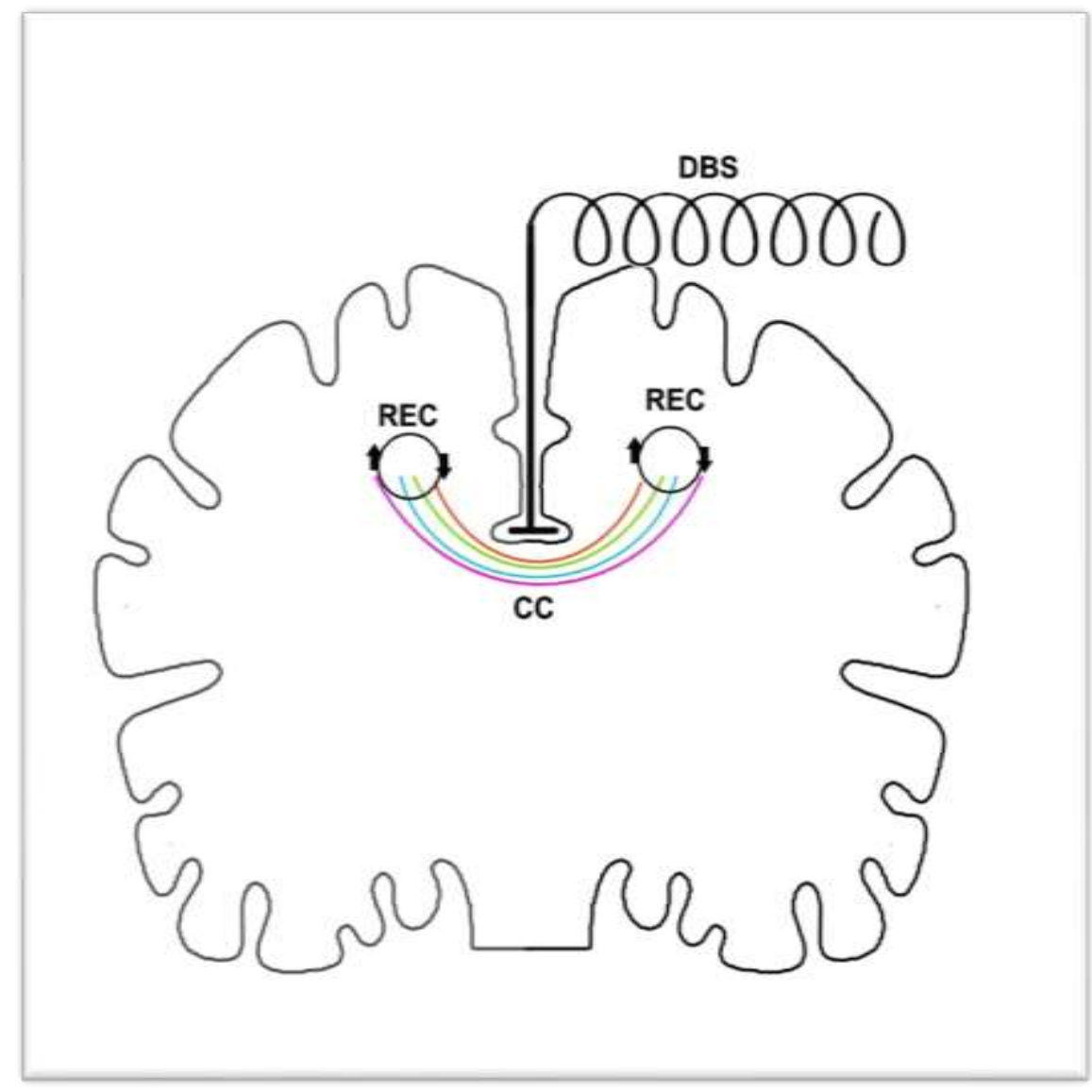

Abbreviations:

$\mathrm{CC}=$ Corpus Callosum, DBS $=$ Deep Brain Stimulation, $\mathrm{REC}=\mathrm{Re}$-entrant circuit

\section{Figure 1: Corpus Callosum, Re-entrant circuits and Deep Brain Stimulation}

The comparison between RECs in AV node and CC is mentioned in Table 2.

\begin{tabular}{|l|c|c|}
\hline & SVT & Seizure in MS patients \\
\hline REC & VICS between Normal \& Accessory pathways & VICS between CC fibers \\
\hline Site of REC & Between upper \& lower halves of the heart & Between right \& left sides of the brain \\
\hline Treatment & Adenosine, DC cardioversion & AEDs, GA, DBS \\
\hline Investigation & Electrophysiology & MRI Brain Scan (CC thinning) \\
\hline
\end{tabular}

\section{Abbreviations:}

$\mathrm{AED}=$ Antiepileptic drug, AV=Atrioventricular, $\mathrm{CC}=$ Corpus callosum, DC= Direct current, DBS=Deep Brain Stimulation, GA=General anesthesia, MRI= Magnetic Resonance Imaging, MS= Multiple sclerosis, REC= Re-entrant circuit, SVT= Supraventricular tachycardia, VICS= Variation in conduction speed,

\section{Table 2: Comparison between Atrioventricular and Corpus Callosum Re-entrant ciruits}

The other significant finding in my experience is that all of MS patients with epilepsy were found to have significant thinning of the CC on MRI brain images. Thinning of the $\mathrm{CC}$ is the evidence that the demyelination process involves CC fibers (Figure 2). 


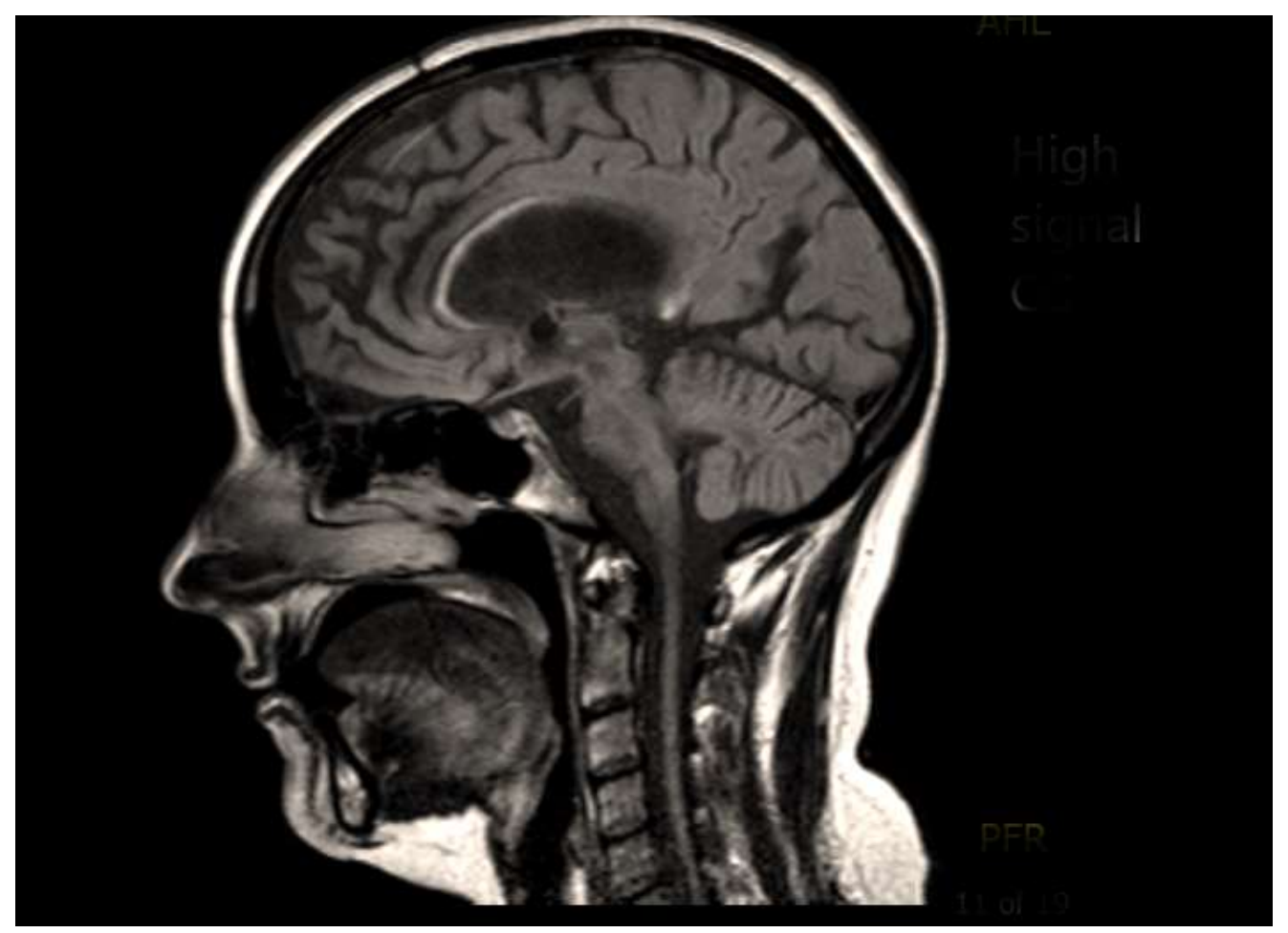

The scan showing significant thinning and high signal of Corpus Callosum in Multiple Sclerosis patient who started having seizures and EEG did not show Interictal Epileptiform discharges

\section{Figure 2: Mid-sagittal MRI Brain Scan}

If this hypothesis is proven, Deep Brain Stimulation (DBS) applies to CC (Figure 1) could be a new treatment in terminating seizures in MS sufferers (like applying Vagal Nerve Stimulator in Epilepsy in general population). DBS to $\mathrm{CC}$ is like a temporary electrical Corpus callosotomy.

\section{Conclusion:}

Demyelination can create VICS in axons. If the VICS axons are adjacent to one another, RECs can be created. If RECs involves CC axons, seizure activity can result. This is my proposed pathophysiology for epilepsy in MS. DBS applying to $\mathrm{CC}$ can be a promising intervention in terminating seizure activity of MS sufferers.

\section{Conflict of Interest}

There is no conflict of interest.
This work is licensed under Creative Commons Attribution 4.0 License

\section{To Submit Your Article Click Here: Submit Manuscript}

DOI: $10.31579 / 2578-8868 / 199$
Ready to submit your research? Choose Auctores and benefit from:

* fast, convenient online submission

* rigorous peer review by experienced research in your field

* rapid publication on acceptance

* authors retain copyrights

* unique DOI for all articles

* immediate, unrestricted online access

At Auctores, research is always in progress.

Learn more https://auctoresonline.org/journals/neuroscience-andneurological-surgery 